\title{
Personnel Development and Assignment Based upon the Technology Calendar Concept
}

\author{
Sven Rottinger and Gert Zülch \\ University of Karlsruhe, ifab-Institute of Human and Industrial Engineering, Kaiserstrasse \\ 12, D-76131 Karlsruhe, Germany. \\ Email: $\{$ sven.rottinger, gert.zuelch\}@ifab.uni-karlsruhe.de.
}

\begin{abstract}
The optimal utilisation of human resources is one of the most important success factors contributing to long-term competitiveness. An essential requirement for the optimal utilisation is a goal-oriented planning of personnel development. The principal intention of personnel development and assignment planning is to cope with technology and product changes. These changes not only demand a quick and flexible adaptation of machinery resources but also that of an existing workforce. In addition to the productions logistical and financial objectives, which are generally in the foreground during the implementation of new technologies and products, the workers' personal concerns should be taken into account. In order to be able to offer a methodology for the continuous adaptation of a workforce to the process of change, the idea of the technology calendar concept is picked up and expanded here. Within this concept, the ifab-Institute of Human and Industrial Engineering at the University of Karlsruhe exploits the possibility of using simulation as a planning tool in order to support a goal-oriented planning of personnel development.
\end{abstract}

Key words: Manufacturing planning, Human-oriented simulation, Personnel development, Technology calendar

\section{IMPORTANCE OF PERSONNEL DEVELOPMENT}

New products and process technologies and a changing manufacturing programme demand a quick and flexible adaptation of the existing workforce. This adaptation is essential for the optimal utilisation of human 
resources which are in many manufacturing systems the most expensive but also the most flexible factor.

However, various enterprises use a traditional form of personnel development in order to adapt their personnel structures to the changes in manufacturing systems. This means that already existing qualification deficiencies are the trigger for development measures. Consequently the elimination of personnel bottlenecks occurs reactively, usually with single, improvised measures.

In contrast to the traditional form, the approach of a synchronised personnel development can be used. According to this concept, development measures are coordinated with the planned product and technology changes from the very beginning. The aim is for all affected workers to possess the necessary qualifications early enough to avoid qualification bottlenecks. For this purpose the technology calendar concept is used to adjust continuous product and technology changes with the personnel development and assignment.

In general, the planning process should encompass several technological phases. Therefore, it is necessary to define timeframes, which allow for a rough planning of the needed number and abilities of a workforce. These timeframes determine when product or technology changes should be expected. Which worker is suitable for further education and how the respective abilities should be achieved is a subject matter related to the determination of qualitative personnel requirements, whereas the number of needed persons is a quantitative issue. If the required qualifications are to be available at the right point in time, it is indispensable that the necessary qualification measures are defined and scheduled appropriately. The qualification concept which has been developed here describes the qualification measures, sorted into target groups, content, qualification costs, and time.

Dependent upon the type of personnel assignment problem to be solved, several instruments have been developed at the ifab-Institute of Human and Industrial Engineering of the University of Karlsruhe, e.g. the personnel-oriented simulation tool ESPE (in German: "Engpassorientierte Simulation von Personalstrukturen"; cf. HEITZ 1994; ZÜLCH 1996; ZÜLCH, VOLLSTEDT 2000). In order to support the described planning process, the possibility of using this simulation tool is exploited. For this purpose, a novel simulation tool has been adapted to the requirements of long-term personnel development and assignment planning. 


\section{FACTORS INFLUENCING PERSONNEL DEVELOPMENT PLANNING}

In order to evaluate the development of a workforce, various criteria can be taken into account. In addition to the productions logistical and financial objectives, which are generally in the foreground during the implementation of new manufacturing technologies and product developments, the workers' personal concerns should also be observed.

\subsection{Continuous Process Technology Changes}

The development of the various product and process technologies is characterised by a further increase in the degree of automation. Furthermore, it can be seen that decentralised manufacturing systems are often used in order to improve flexibility and reactivity. This refers to an increased integration of indirect functions, such as maintenance and quality control, into the manufacturing process.

The technological developments usually provide important impulses for personnel development: Specialists who are qualified only for few work tasks are no longer the focus of interest. Rather, workers who can also take on up-stream or down-stream work tasks are desired to a far greater extent. This does not only imply an adoption of more, similarly structured work tasks, as in job enlargement, rather in particular the adoption of more responsibility, as in a vertical job enrichment (ULICH 1998, p. 159).

Another important impulse for personnel development planning is the increased likelihood of machinery failures during the start-up of new equipment. In order to avoid downtime, the personnel responsible for maintenance tasks must be present in adequate numbers and with the necessary qualifications.

\subsection{Continuous Product Changes}

In order to remain competitive in the market, a production enterprise must further develop its palette of available products and increase the number of variants according to market demands. The continuous product development has numerous effects upon future personnel developments:

On the one hand, questions regarding the quantitative personnel demands must be clarified when considering the development of product figures. On the other hand, the introduction of new product variants, the further development of existing products, and even new process technologies lead to more complex work requirements, which cannot be managed without a targeted, qualitative personnel development. 


\subsection{Considering Personnel Aspects}

In order to take the preferences and restrictions of the existing workforce into account during development planning, the simulation procedure ESPE offers an appropriate approach (cf. HEEL 1999, p. 96). This simulation package includes a preference system, which permits the modelling of personal preferences and restrictions for each required qualification. This preference system has been supplemented with worker development potentials for future work tasks in order to support personnel development planning, and was implemented in ESPE-PE (ESPE for Personnel Development). The simulation procedure $E S P E-P E$ can thus make a clear statement as to which person is best suited for the needed qualifications of an upcoming work task. The development potential can thereby be determined from worker surveys or from the guess of a superior.

Another personnel aspect is the sequential completeness of work functions (cf. HACKER 1987, p. 44). Sequential completeness refers to a work task which includes, in addition to the execution function, also upstream and downstream functions, for example set-up and maintenance functions as well as control functions. In particular persons without job alternation will obtain in the procedure a preferred enlargement of their abilities, on condition that these persons are suitable for further qualification.

\section{COORDINATION OF MEASURES USING THE TECHNOLOGY CALENDAR CONCEPT}

\subsection{Synchronised Personnel Development}

Numerous concepts for the integration of product and technology development into organisations development can be found in the literature (HAYES, WHEELRIGHT 1984, p. 197; SAVÉN, OLHAGER 2002, pp. 375). In particular various technology calendar concepts have been presented. These concepts permit the synchronisation of technology and product changes. The approaches differ with respect to their application areas and objectives (BURGSTAHLER 1997, p. 69).

However, none of these concepts consider the integration of personnel development planning in the process of change. In order to be able to offer a continuous methodology for the aforementioned problem with respect to the integration of personnel development in the process of change, the idea of the technology calendar concept was picked up and expanded. The concept has thereby been supplemented in order to coordinate personnel develop- 
ment measures, in the sense of a personnel development, which is synchronised with product and technology developments.

The technology calendar concept, which is implemented in ESPE-PE, recognises four sectors (cf. Figure 1): In the product programme sector the new products to be planned are listed along with the date of their planned production start. In the product and process technology sectors the new technologies are listed with the latest date for their application maturity (cf. BURGSTAHLER, 1997, p. 109). Due to the fundamental need for the integration of the personnel resources into this planning process, the personnel development has been incorporated into the fourth sector. In order to coordinate personnel development measures, the production system can be simulated for each modelled date of a product and technology development.

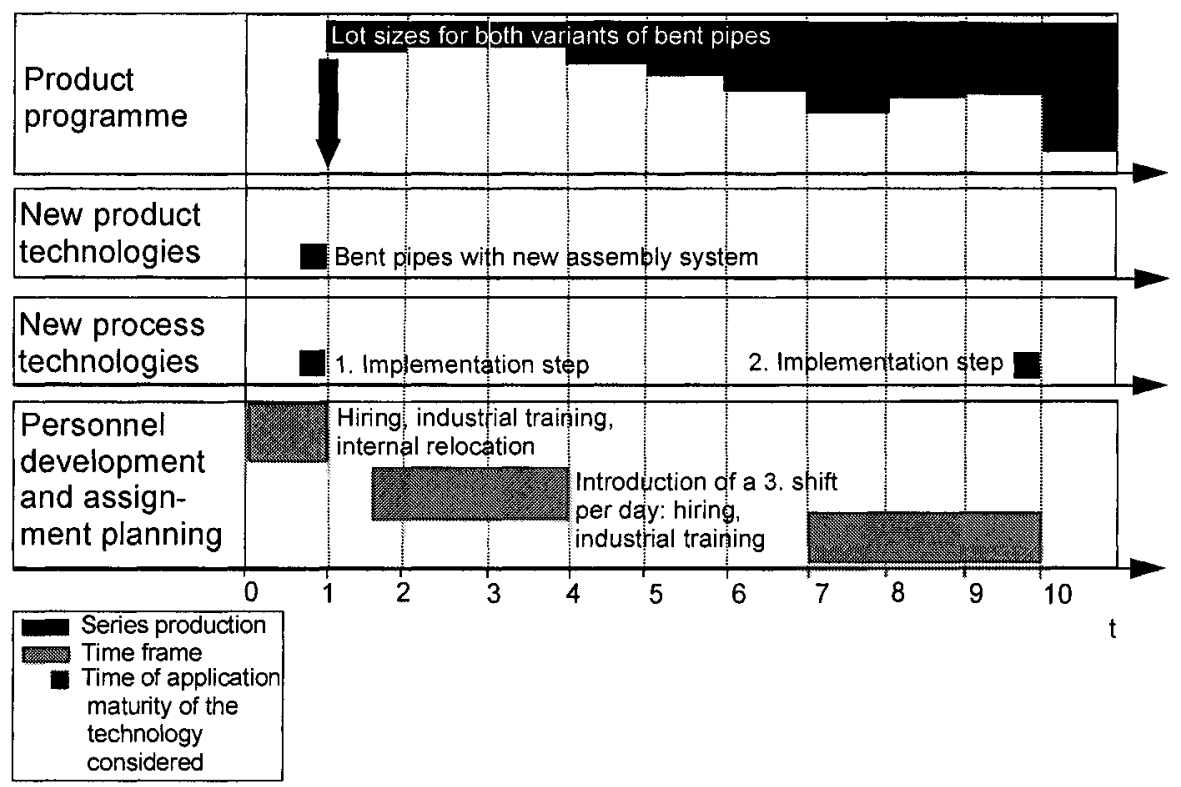

Figure 1. Technology calendar with synchronised timeframes for personnel development (Source: ROTTINGER, ZÜLCH 2003, p. 56)

\subsection{Personal-oriented Modelling of Manufacturing Systems}

In order to be able to evaluate the effects of personnel development measures on the manufacturing system using the simulation procedure $E S P E-P E$, an appropriate modelling of the technology and product change as well as a modelling of the personnel structure is necessary. The function- 
equipment-matrix of a manufacturing system (cf. Figure 2), used for the modelling of personnel structures, is a significant input mask. This matrix contains all functional elements appearing in the manufacturing programme for a specific time period. A functional element refers to the requirement of a specific function at a certain workplace or machine, e.g. the set-up function of a milling machine. Thus, the ability of a worker is defined by the set of all functional elements he can execute. This high degree of detail for modelling of the workers' abilities allows for personnel related bottlenecks, occurring after a technology or product change, to be identified in a simulation study and the according personnel development measures to be derived.

The problem of developing and assigning workers to functions and workplaces is characterised, on the one hand, by a large number of possibilities for varying the abilities of the needed workforce and, on the other hand, by a large number of different possibilities for allocating persons to work functions. Of course, the chosen assignment has an important effect on labour costs per manufactured unit and the achievement of logistical goals.

\subsection{Objectives and Evaluation of Personnel Development}

ESPE-PE supports an evaluation of alternative personnel structures for a specific evaluation period. An evaluation period is determined by the proximate point in times $t$ and $t+1$ and considers the average lead time degree of orders, the system output and the average workload as logistical goals, and the calculated labour cost as well as the personnel adjustment costs as financial goals (see for further details ZÜLCH, GROBEL, JONSSON 1995, pp. 311). In addition to the logistical and financial goals, personnel-oriented aspects can also be evaluated, e.g. concerning personnel development potential or the completeness of work functions.

In order to evaluate a personnel development concept over multiple stages of technology and product changes it is not sufficient to select the best planning solution for each evaluation period separately. Beyond this it is necessary to take for each evaluation period several alternative planning solutions into account and to derive alternative personnel development paths for the entire sequence of changes. This approach ensures the generation of a personnel development concept, which contains the best solution over all development stages. 


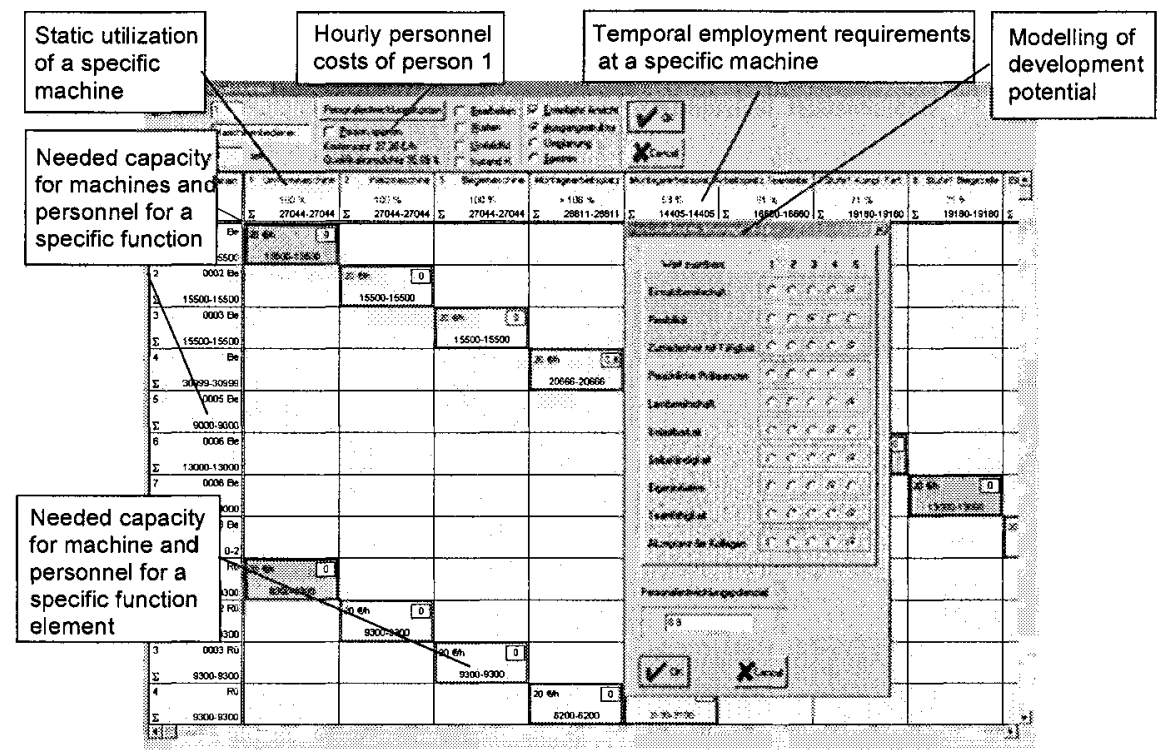

Figure 2. Function-equipment-matrix

\section{TECHNOLOGY AND PRODUCT CHANGES FOR A COMPONENT SUPPLIER AS AN EXAMPLE}

In the following case study the technology calendar concept is used for a component supplier from the automotive supply industry. In this project a personnel development concept which considers multiple stages of technology and product changes should be generated.

\subsection{Problem Description}

The considered production enterprise was faced with broad modifications to a specific manufacturing system. In the initial situation numerous component variants were manufactured in small lot sizes. In addition to this initial manufacturing programme, an order with large lot sizes and only two variants was envisaged by a certain customer from the automotive industry. This would possibly justify the application of a new manufacturing technology allowing for an assembly process without complex welding procedures. This new technology, resulting in an automated workplace, could be implemented in two stages. 
In addition to this technology change, a quantitative development of the regarded product variants had to be modelled in accordance with the quantities demanded from the automotive company. Aside from a continuous quantitative production increase over time, one significant rise in output which would occur after the end of summer holidays had to be considered. The second significant rise was envisaged in a specific month in 2004, at which time the second implementation stage had to be concluded so that the required quantity could be produced.

\subsection{Personnel Development Concept}

In accordance with these multiple stages of technological changes, various scenarios were built. Their main aspects are the following: In order to obtain the personnel qualifications needed for the new manufacturing technology on time, a personnel development concept has to be set up. All qualitative and quantitative aspects of the personnel development, dependent upon the implementation stages of the new technology and the monthly enlargement of the production volume have to be defined in this concept.

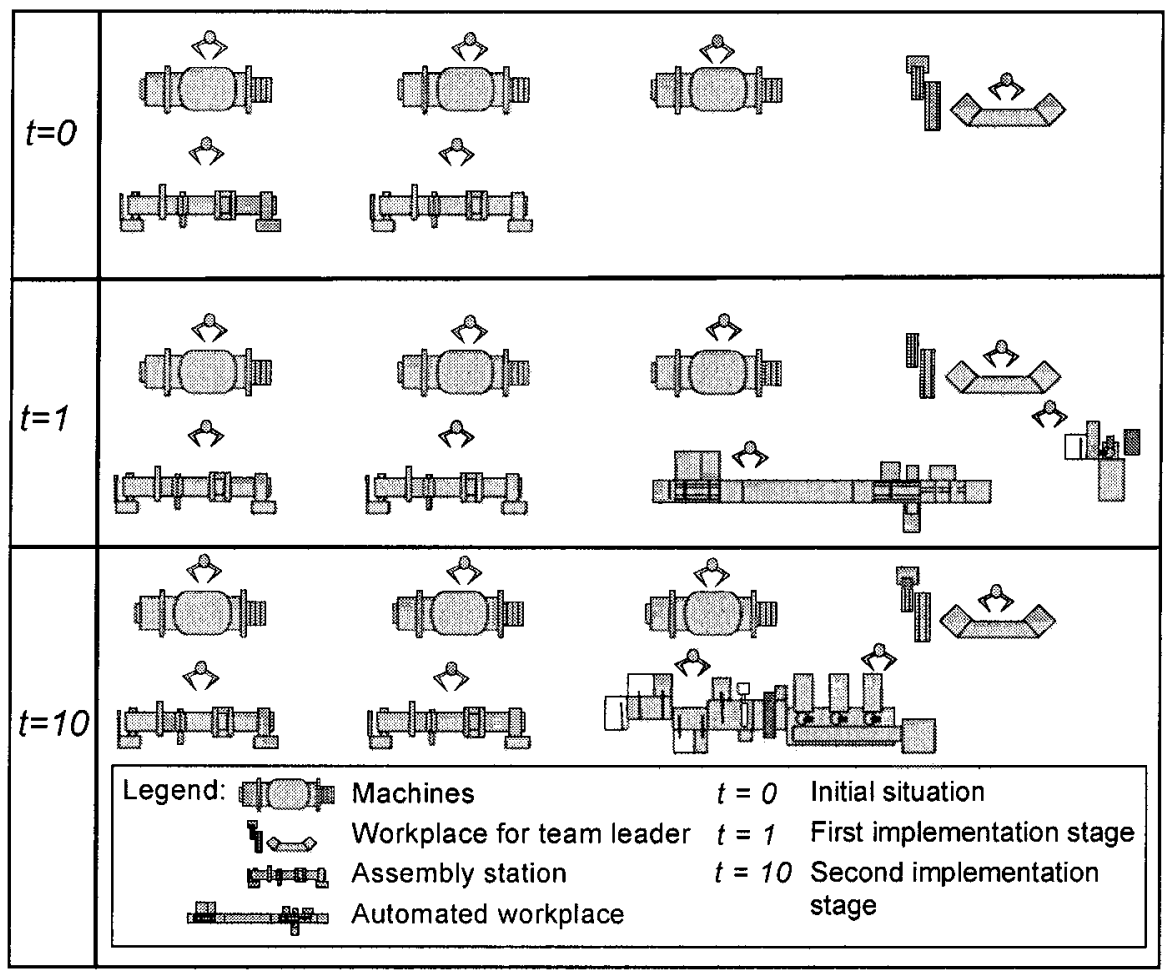

Figure 3. Development of the manufacturing system 
Furthermore, an increased probability of machine failure after each implementation stages of the automated workplace has to be considered. In order to reduce machine disturbances, especially during the early introduction stages of the new technology, an adequate number of maintenance personnel have to be planned for the new tasks

The initial situation as well as the scenarios for the upcoming technology and product changes have been modelled and simulated in ESPE-PE. For each point in time of a technology or product change the scenarios have been evaluated and, where applicable, an adaptation of the existing personnel structure has been regarded.

The results contain a personnel development concept with the latest point in time for the necessary measures as well as the target group and content of all necessary measures for personnel development. Beyond continuous training of the existing staff, one measure includes the acquisition of skilled workers from the external employment market. The reason for the acquisition of additional workers is the high qualification requirements for the setup and maintenance functions, created by the new technology, which cannot be fulfilled by the existing workforce while also taking their qualification preferences and restrictions into account. Furthermore, several restrictions for an extension of qualification of the present staff become evident, resulting from an assessment of the qualification development potential. The main reason for the qualification restrictions of the existing workforce is the high contingent of workers originating from external trades. Due to their lack of technical qualifications, such workers are only suitable for simple operating tasks.

\begin{tabular}{|c|c|c|c|}
\hline & Measures & Type of Personnel & Machine/Function Element \\
\hline \multirow[t]{3}{*}{$t=1$} & $\begin{array}{l}\text { External personnel hiring } \\
\text { and industrial training }\end{array}$ & $\begin{array}{l}1 \text { Equipment } \\
\text { manager } \\
2 \text { Equipment } \\
\text { operators }\end{array}$ & $\begin{array}{l}\text { AW1, AW2: } \\
\text { Set-up, adjustment, control, minor } \\
\text { disturbance elimination, maintenance } \\
\text { AW1, AW2: } \\
\text { Material preparation, set-up, } \\
\text { machine rigging }\end{array}$ \\
\hline & $\begin{array}{l}\text { Internal relocation and } \\
\text { industrial training }\end{array}$ & 1 Team leader & $\begin{array}{l}\text { AW1, AW2: } \\
\text { Set-up, minor disturbance removal, } \\
\text { maintenance }\end{array}$ \\
\hline & $\begin{array}{l}\text { Instruction at the } \\
\text { equipment }\end{array}$ & $\begin{array}{l}1 \text { Machine operator } \\
2 \text { Equipment } \\
\text { operators }\end{array}$ & AW1, AW2: Equipment fitting \\
\hline$t=4$ & $\begin{array}{l}\text { External personnel hiring } \\
\text { and industrial training }\end{array}$ & $\begin{array}{l}1 \text { Equipment } \\
\text { manager }\end{array}$ & $\begin{array}{l}\text { AW1, AW2: } \\
\text { Set-up, adjustment, control, minor } \\
\text { disturbance elimination, maintenance }\end{array}$ \\
\hline
\end{tabular}

Legend: AW1, AW2 Automated Workplace

Figure 4. Personnel development concept 
The derived measures contained an important input for those responsible for planning. Especially the determination of the time frame for the acquisition from the external employment market and the consequent realisation of this measure were decisive for the successful implementation of the automated workplace.

\section{SUMMARY AND FURTHER RESEARCH}

In order to be able to react quickly to product and technology changes, the flexibility potential of the available personnel structure must be registered, and exploited during the continuous planning process. Practical industrial experience shows that personnel development measures are often reactive or are carried out in an ad hoc or improvised manner. A simulation supported planning tool, with which measures for personnel assignment and development planning can be commenced in a targeted and timely manner, has been compiled here in order to counteract reactive personnel development.

The fundamental idea behind the technology calendar concept, which was originally conceived for the coordination of long-term change processes, can also be transferred onto problems arising from a shortened planning horizon in order to cope with demands of a market-driven production with increasing product diversity, ever shorter delivery times and higher delivery reliability. In order to be able to react quickly to the short-term changes to the sales market, many production enterprises turn to decentralised organisational structures.

However, as a result of a weekly or even daily varying order programme, these decentralised organisational structures are faced with a fluctuating workload. A future research requirement can be seen in the assignment of workers from weakly loaded organisational structures to organisational structures with higher personnel utilisation as a compensation for a daily varying order programme. Thus, the modelling of weekly or even daily variations in the quantity and type of the order programme, and the support of associated personnel assignment problems must be undertaken.

Building upon this, a systematic procedure, which supports the planning of short-term personnel assignment in decentralised organisations structures, should be developed. An objective of priority for this procedure is to plan group structures which, on account of their qualification, are able to exchange individual workers between the individual, decentralised production units in order to achieve high personnel utilisation, a complete processing of the manufacturing programme as well as low lead times. 


\section{ACKNOWLEDGEMENTS}

The long-term generation of the personnel-oriented simulation tool ESPE was possible under the umbrella of the Special Research Area 346 "Computer-integrated design and manufacturing of parts". This research area was sponsored by the German Research Association (Deutsche Forschungsgemeinschaft - DFG) from 1990 - 2002. With this support the base for the presented possibilities for personnel development and assignment was created. With the objective of transferring the results of the fundamental research into industrial practice the Transfer Unit 48 emerged from the Special Research Area was established. The results of this article were gathered within the context of this transfer unit.

\section{REFERENCES}

BURGSTAHLER, Bernd:

Synchronisation von Produkt- und Produktionsentwicklung mit Hilfe eines Technologiekalenders.

Braunschweig, Univ. Diss., 1997.

HACKER, Winfried:

Software-Ergonomie: Gestalten rechnergestützter Arbeit?

In: Software Ergonomie 1987.

Edts.: SCHÖNPFLUG, Wolfgang.

Stuttgart: B.G. Teubner Verlag, 1987, pp. 31-54.

HAYES, Robert H.; WHEELRIGHT, Steven C.:

Restoring our Competitive Edge, Competing through Manufacturing.

New York NY: John Wiley and Sons, 1984.

HEEL, Jochen:

Reorganisation des Personaleinsatzes mit Hilfe der personalorientierten Simulation.

Aachen: Shaker Verlag, 1999.

(ifab-Forschungsberichte aus dem Institut für Arbeitswissenschaft und Betriebsorgani-

sation der Universität Karlsruhe, Vol. 18)

HEITZ, Max-Jürgen:

Ein engpaßorientierter Ansatz zur simulationsunterstützten Planung von

Personalstrukturen.

Karlsruhe Univ., Diss. 1994.

(ifab-Forschungsberichte aus dem Institut für Arbeitswissenschaft und Betriebsorgani-

sation der Universität Karlsruhe, Vol. 7)

ROTTINGER, Sven; ZÜLCH, Gert:

Personnel Development and Assignment Based upon the Technology Calendar Concept.

In: Human Aspects in Production Management.

Eds.: ZÜLCH, Gert; STOWASSER, Sascha; JAGDEV, Harinder S.

Aachen: Shaker Verlag, 2003, pp. 53-59.

(esim - European Series in Industrial Management, Volume 5) 
SAVÉN, Ruth Sara; OLHAGER, Jan:

Integration of Product, Process and Functional Orientations: Principles and a Case Study. IFIP WG5.7 International Conference on Advanced Production Management Systems, APMS 2002, Pre-prints.

Eds.: JAGDEV, Hari u.a.

Eindhoven: Technische Universiteit, 2002, pp. 375-389.

ULICH, Eberhard:

Arbeitspsychologie.

Stuttgart: Schäffer-Poeschel Verlag, 4. edition 1998.

ZÜLCH, Gert:

A Heuristic Solution to the Personnel Structure Problem.

In: ORBEL10, Proceedings of the Tenth Conference on Quantitative Methods for Decision Making.

Ed.: JANSSENS, Gerrit K.

Brussels: Belgian Operations Research Society, 1996.

ZÜLCH, Gert; VOLLSTEDT, Thorsten:

Personnel-integrated and Personnel-orientated Simulation - A New Guideline of the

German Association of Engineers.

In: Information and Communication Technology (ICT) in Logistics and Production

Management.

Eds.: STRANDHAGEN, Jan Ola; ALFNES, Erlend.

Trondheim: Norwegian University of Science and Technology, Department of Production and Quality Engineering, 2000, pp. 185-192.

ZÜLCH, Gert; GROBEL, Thomas; JONSSON, Uwe:

Indicators for the Evaluation of Organizational Performance.

In: Benchmarking - Theory and Practice.

Ed.: ROLSTADÅS, Asbjørn.

London et al.: Chapman \& Hall, 1995, pp. 311-321. 